\title{
Validation of a portable indirect calorimetry system for measurement of energy expenditure in sick preterm infants
}

\author{
G J Shortland, P J Fleming, J H Walter
}

\begin{abstract}
A portable indirect calorimeter adapted from adult use was validated for use in preterm infants. Oxygen consumption $\left(\forall o_{2}\right)$ and carbon dioxide production $\left(\dot{\mathrm{V}} \mathrm{CO}_{2}\right)$ were subsequently measured in 16 preterm infants breathing spontaneously in room air (canopy mode) and in nine preterm infants receiving intermittent positive pressure ventilation (ventilator mode). Validation of the system was performed using a gas injection technique with nitrogen to simulate $\dot{V}_{2}$ and carbon dioxide for $\dot{\mathrm{V}} \mathrm{CO}_{2}$. Mean errors in validation of the canopy mode were $1.4 \%$ and $0.2 \%$ for $\dot{V O}_{2}$ and $\dot{\mathrm{V}} \mathrm{CO}_{2}$ with limits of agreement of $0.6(+2 S D) \mathrm{ml} / \mathrm{min}$ and -1.3 (-2SD) $\mathrm{ml} / \mathrm{min}$, and 0.9 (+2SD) $\mathrm{ml} / \mathrm{min}$

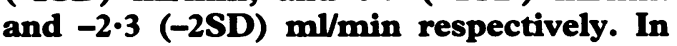
validation of the ventilator mode mean errors were $-1 \cdot 8 \%$ and $-5 \cdot 05 \%$ for $\dot{V}_{2}$ and $\dot{\mathrm{VCO}}_{2}$ with limits of agreement of 1.02 (+2SD) $\mathrm{ml} / \mathrm{min}$ and $-0.74(-2 S D) ~ \mathrm{ml} / \mathrm{min}$, and 0.93 (+2SD) $\mathrm{ml} / \mathrm{min}$ and -1.45 (-2SD) $\mathrm{ml} / \mathrm{min}$ respectively.

Values of $\dot{\mathrm{V}} \mathrm{O}_{2}$ and $\dot{\mathrm{V}} \mathrm{Co}_{2}$ in 16 preterm infants in the canopy mode were 6.2 $\mathrm{m} / \mathrm{kg} / \mathrm{min}(0.5 \mathrm{1SD})$ and $6.7 \mathrm{~m} / \mathrm{kg} / \mathrm{min}$ $(0.6$ 1SD) and in nine preterm infants in the ventilator mode $4.98 \mathrm{ml} / \mathrm{kg} / \mathrm{min}(1.09$ 1SD) and $4.74 \mathrm{ml} / \mathrm{min} / \mathrm{kg}$ (1.08 1SD) respectively. Mean energy expenditure was $45.5 \mathrm{kcal}(191 \mathrm{~kJ}) \mathrm{kg} / \mathrm{day}$ for infants measured in the canopy mode and 35.5 kcal $(149 \mathrm{~kJ}) / \mathrm{kg} /$ day for ventilated infants. This metabolic system can be adapted for use in the newborn but accuracy is reduced when it is used in those weighing less than $1000 \mathrm{~g}$.
\end{abstract}

(Arch Dis Child 1992; 67:1207-11)

The measurement of the rate of oxygen consumption $\left(\mathrm{VO}_{2}\right)$ and carbon dioxide production $\left(\dot{\mathrm{V}} \mathrm{CO}_{2}\right)$ by indirect calorimetry may be used to calculate a number of parameters important in research into human metabolism. These include the respiratory quotient (RQ), energy expenditure, and rates of fat and carbohydrate utilisation. ${ }^{1} \dot{\mathrm{VCO}}_{2}$ is also required where carbon labelled stable isotopes are infused for the measurement of substrate oxidation and estimation of whole body protein turnover. ${ }^{2}$ The first calorimeters used a closed circuit design ${ }^{3}$ and have progressed to open circuit indirect calorimeters ${ }^{4}$ and ventilated hood or canopy systems. ${ }^{5}$ Indirect calorimetry has been widely used in metabolic studies in adults and has provided much information about metabolic processes in both health ${ }^{6}$ and disease. ${ }^{7}$ Studies in children and infants are technically more difficult and this is particularly so for sick preterm infants. However a knowledge of energy expenditure and rates of substrate utilisation in this latter group is of vital importance in determining optimal environmental conditions and appropriate feeding regimens. There at present exists a paucity of calorimetry data on sick, and particularly ventilated, preterm infants.

Many factors have been described that may influence the measurement of energy expenditure in the infant including the effect of feeding, ${ }^{8} 9$ medical procedures, ${ }^{10}$ sleep state, ${ }^{11}$ maturity, ${ }^{12}$ and type of feed. ${ }^{13}$ Variability in measurements from day to day have been reported $^{13}$ and investigation of infants over five days have been performed. ${ }^{14}$ These studies have concentrated on healthy growing infants and there is a need for suitable apparatus to be used with the sick preterm infant for similar work. The difficulties that arise when using indirect calorimetry in low birthweight infants are primarily due to their very small respiratory volumes. In ventilated hood or canopy systems the change in gas concentrations for infants of between 1000 and $2500 \mathrm{~g}$ will be in the order of 0.05 to $0.15 \%$ when a canopy ventilation rate of about $10 \mathrm{l} / \mathrm{min}$ is used. It is important that any system used to measure $\dot{\mathrm{VO}}_{2}$ and $\dot{\mathrm{V}} \mathrm{CO}_{2}$ must be able to accurately determine such small differences. Previous investigators have reported variations from expected values in $\dot{\mathrm{Vo}}_{2}, \dot{\mathrm{V}} \mathrm{CO}_{2}$ and $\mathrm{RQ}$ of between 2 to $5 \%$. $^{15} 16$

In contrast to the measurement of $\dot{\mathrm{Vo}}_{2}$ and $\dot{\mathrm{V}} \mathrm{CO}_{2}$ in well, stable infants, there are few reports of their measurements in the ventilated, newborn infants. Lucas et al have reported measurement of $\dot{\mathrm{V}} \mathrm{CO}_{2}$, but not $\dot{\mathrm{V}} \mathrm{O}_{2}$, on 11 ventilated newborn infants between 26 and 32 weeks' gestation. ${ }^{17}$ They have suggested that by measuring $\mathrm{VCO}_{2}$ alone and taking $\mathrm{RQ}$ as 0.85 that errors in the calculation of energy expenditure would be no greater than $14 \%$. In an artificial test lung recovery rates of carbon dioxide ranged from 97 to $99 \%$. Richardson et al measured $\dot{\mathrm{Vo}}_{2}$, but not $\dot{\mathrm{V}} \mathrm{CO}_{2}$, by an oxygen replenishment technique in 14 infants with respiratory distress syndrome. ${ }^{18}$ Combined measurements of $\dot{\mathrm{VO}}_{2}$ and $\dot{\mathrm{VCO}}_{2}$ in sick infants, young children, and the newborn have been made using a metabolic monitor that employs a pneumotachometer, zirconium oxide oxygen sensor, and infrared carbon dioxide sensor. ${ }^{19} 20$ In those systems the 
assessment of $\dot{\mathrm{VO}}_{2}$ is critically dependent on accurate measurement of the oxygen concentration entering the system and that the oxygen supplied is at an absolute constant concentration. Small changes in the ambient oxygen of $0.05 \%$ may lead to large errors of 30 to $100 \%$ in $\dot{\mathrm{Vo}}_{2}$. Measurements of $\dot{\mathrm{V}} \mathrm{CO}_{2}$ are less subject to error because of the low ambient concentrations of carbon dioxide. The lack of suitable validations in indirect calorimetry systems have been highlighted previously. ${ }^{21}$ In order to undertake metabolic studies in sick low birthweight infants we have validated a portable system (Deltatrac Metabolic Monitor, Datex IC, Finland) that has been adapted for use in children by changing the flow rate through the apparatus, and tested it for its suitability for ventilated and non ventilated preterm infants. It is designed to be used as a ventilated canopy system, for those infants not requiring ventilatory support or oxygen therapy, and also in a closed circuit for ventilated infants.

\section{Patients and methods}

MONITOR

In the open canopy mode room air is drawn into a Perspex hood by a centrifugal fan at a constant flow rate of $10.3 \mathrm{1} / \mathrm{min}$ and pumped into the monitor. The Perspex hood covers the infant and a plastic skirt further covers the area of cot surrounding the infant creating a partial seal. Concentrations of carbon dioxide and oxygen are measured both in ambient room gas entering the hood, via an external sampling line, and in gas leaving the hood by an infrared carbon dioxide sensor and a paramagnetic differential oxygen sensor. With a known constant flow rate $(\mathrm{Q}), \dot{\mathrm{Vo}}_{2}$ and $\dot{\mathrm{V}} \mathrm{CO}_{2}$ can be calculated from the difference between inspired and expired values; see equations (1) and (2):

(1) $\dot{\mathrm{Vo}}_{2}=\left(\mathrm{Q} /\left(1-\mathrm{FIO}_{2}\right)\right) \times\left(\mathrm{Fo}_{2}-\left(\mathrm{FIO}_{2} \times \mathrm{FCO}_{2}\right)\right)$

(2) $\dot{\mathrm{V}} \mathrm{CO}_{2}=\mathrm{Q} \times\left(\mathrm{FECO}_{2}-\mathrm{FICO}_{2}\right)$

Where $\mathrm{FIO}_{2}$ is the concentration of inspired oxygen, $\mathrm{FEO}_{2}$ the concentration of expired oxygen, $\mathrm{FICO}_{2}$ the concentration of inspired carbon dioxide, $\mathrm{FECO}_{2}$ the concentration of expired carbon dioxide, $\mathrm{FO}_{2}$ is $\mathrm{FIO}_{2}-\mathrm{FEO}_{2}$ and $\mathrm{FCO}_{2}$ is $\mathrm{FECO}_{2}-\mathrm{FICO}_{2}$. The formula for $\dot{\mathrm{V}}{ }_{2}$ includes the Haldane transformation.

In the ventilator mode gases expelled from the ventilator are collected from the expiratory port and pass to a mixing chamber via wide bore tubing and a two litre low pressure reservoir (Ohmeda anaesthetic rebreathing bag) which limits pressure and flow oscillations in the system. Carbon dioxide concentration is measured in the mixing chamber and again after dilution to the known total flow rate. Thus by measurement of carbon dioxide dilution the minute expiratory flow rate can be calculated. $\dot{\mathrm{V}} \mathrm{CO}_{2}$ is calculated from the formula identical to that shown previously.

Inspired oxygen concentration is measured from a sampling line, placed in the inspiration limb of the ventilator circuit, and the differ- ence between this concentration and the mixed gas in the mixing chamber from the expiratory limb is measured using the differential paramagnetic oxygen sensor. By use of the Haldane transformation the $R Q$ can be calculated and $\dot{\mathrm{Vo}}_{2}$ defined; see equations (3) and (4).

(3) $\mathrm{RQ}=\left(\dot{\mathrm{V}} \mathrm{CO}_{2} / \dot{\mathrm{VO}}_{2}\right) \frac{1-\mathrm{FIO}_{2}}{\left[\left(\mathrm{FIO}_{2}-\mathrm{FEO}_{2}\right) / \mathrm{FECO}_{2}\right]-\mathrm{FIO}_{2}}$

(4) $\dot{\mathrm{V}} \mathrm{o}_{2}=\mathrm{RQ} / \dot{\mathrm{VCO}}_{2}$

Figures 1 and 2 summarise the operating conditions.

All values are converted to standard temperature $\left(0^{\circ} \mathrm{C}\right)$ and pressure $(760 \mathrm{~mm} \mathrm{Hg})$ dry (STPD). The metabolic monitor uses tubing that is freely permeable to water vapour and thus equalises the water vapour pressure of the gas inside with that of the ambient air. All gas samples, including dry calibration and validation gases, pass through this tubing. Thus all measurements and calibrations are under identical conditions of humidity. Further detailed information of operating conditions and formulas used for calculations can be obtained. ${ }^{22}$

\section{VALIDATION}

The constant flow of the system was measured by burning a $5 \mathrm{ml}$ volume of $95 \%$ Analar grade ethanol $\left(\mathrm{CH}_{3} \mathrm{CH}_{2} \mathrm{OH}\right)$ in a glass test lung (supplied by Datex, Finland) attached to the system. From a known volume of ethanol the expected oxygen consumption and carbon dioxide production are calculated; see equation (5):

$$
\text { (5) } \mathrm{CH}_{3} \mathrm{CH}_{2} \mathrm{OH}+3 \mathrm{O}_{2}=2 \mathrm{CO}_{2}+3 \mathrm{H}_{2} \mathrm{O}
$$

As the volume occupied by a mol or $g$ molecular weight of any gas at standard conditions is 22.414 litres (l) then it may be predicted that $1 \mathrm{~g}$ of ethanol consumes $3 \times 22 \cdot 414 / 46.069=1.46 \quad 1 \quad \mathrm{O}_{2} \quad$ (STPD) and produces $2 \times 22 \cdot 414 / 46 \cdot 069=0.973 \quad 1 \quad \mathrm{CO}_{2}$ (STPD)

This can be compared with the values measured by the apparatus and appropriate calibrations made. It was not possible with the system provided to reproduce rates of $\mathrm{VCO}_{2}$ and $\dot{\mathrm{V}} \mathrm{O}_{2}$ equivalent to those found in the neonate so this system was only used for calibration of the constant flow. Complete combustion of the ethanol was noted by the presence of a completely blue and even flame. Burning time for the ethanol was approximately 30 minutes.

To assess the accuracy of the measurement of $\dot{\mathrm{V}} \mathrm{O}_{2}$ and $\dot{\mathrm{V}}_{2}$ in the canopy mode, at rates similar to those produced by preterm infants, nitrogen and carbon dioxide were infused at known rates into the canopy using certified calibration gas (Cryoservice Ltd, $25 \cdot 2 \% \pm 0 \cdot 5 \%$ carbon dioxide and $74 \cdot 8 \% \pm 1 \cdot 5 \%$ nitrogen) and a certified precision flowmeter scaled for this gas mixture (Rotameter 1100 series, KDG Instruments). Appropriate corrections 


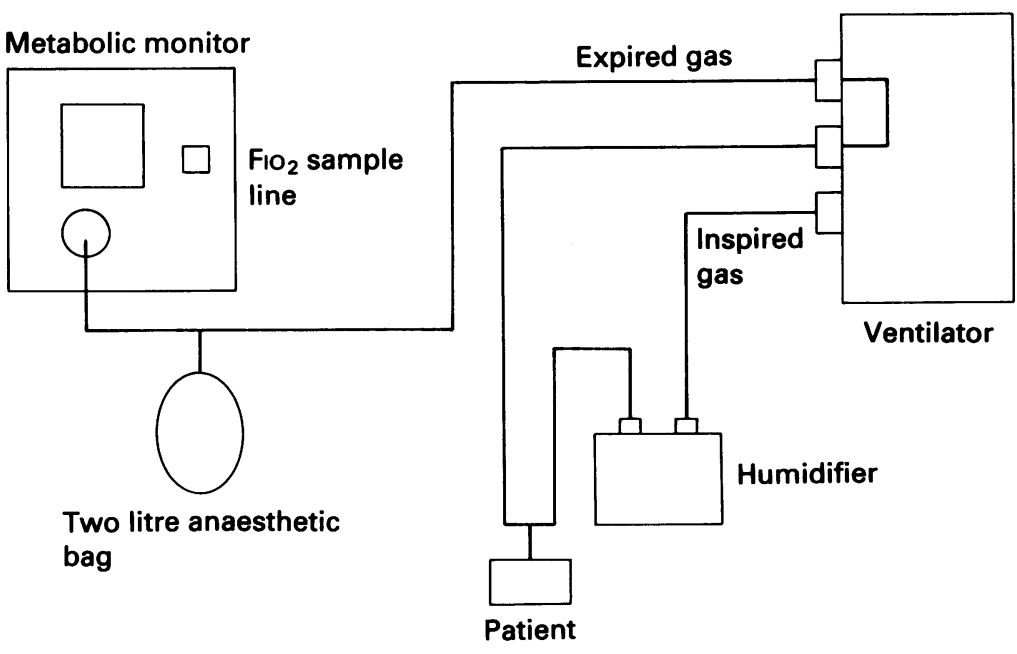

Figure 1 Operating conditions for the ventilator mode.

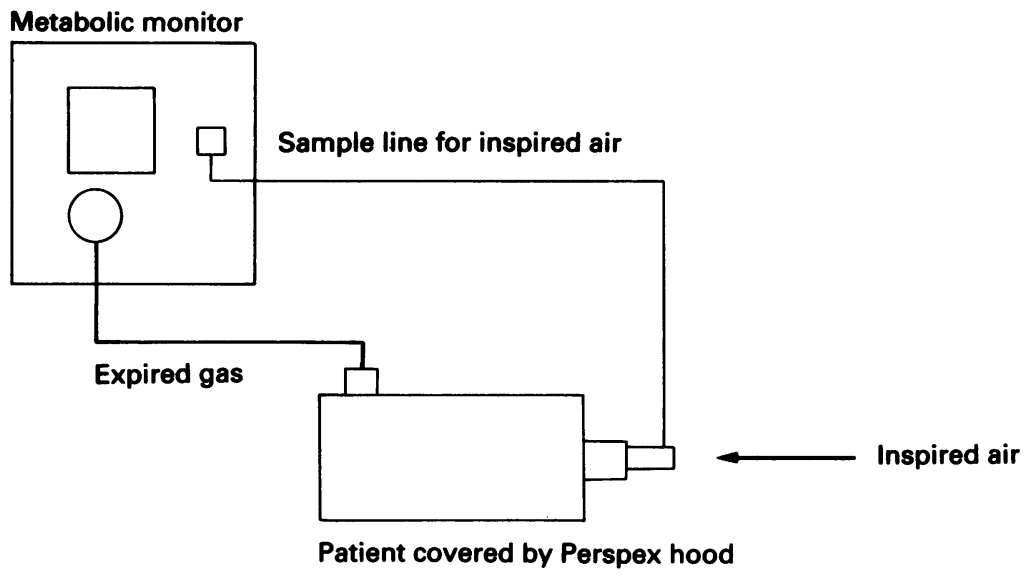

Figure 2 Operating conditions for the canopy mode.

were made for operating temperature and pressure to give gas flows at standard temperature and pressure. In the ventilator mode gas was infused into the ventilator circuit via an artificial glass lung of compliance similar to that of an infant of $1500 \mathrm{~g}$ with respiratory distress syndrome. The ventilator was connected to gas supplies and humidifier in the normal way. With known infusion rates the injection of nitrogen and carbon dioxide will simulate $\dot{\mathrm{VO}}_{2}$ and $\mathrm{VCO}_{2}$; see equations (6) and (7).

(6) $\dot{\mathrm{V}} \mathrm{O}_{2}=\left(\mathrm{FIO}_{2} /\left(1-\mathrm{FIO}_{2}\right)\right) \times \dot{\mathrm{w}} \mathrm{N}_{2}$

(7) $\dot{\mathrm{V}} \mathrm{CO}_{2}=\dot{\mathrm{w}} \mathrm{CO}_{2}\left(\dot{\mathrm{w}} \mathrm{CO}_{2}=\mathrm{CO}_{2}\right.$ injection)

Where $\dot{w}_{2}$ is the nitrogen injection $(\mathrm{ml} / \mathrm{min}$ ) and $\dot{w} \mathrm{CO}_{2}$ is the carbon dioxide injection ( $\mathrm{ml} / \mathrm{min})$.

For the canopy system $\dot{\mathrm{V}} \mathrm{O}_{2}$ and $\dot{\mathrm{V}} \mathrm{CO}_{2}$ rates were simulated over a range of 5 to $24 \mathrm{ml} / \mathrm{min}$ and 4 to $30 \mathrm{ml} / \mathrm{min}$ respectively and for the ventilated system 4 to $50 \mathrm{ml} / \mathrm{min}$ and 3 to 34 $\mathrm{ml} / \mathrm{min}$ respectively.

\section{PATIENTS}

Determinations of $\dot{\mathrm{V}}_{2}$ and $\dot{\mathrm{V}} \mathrm{CO}_{2}$ were made in 16 infants using the canopy mode over a period of approximately one hour. Gestational age varied between 28 to 33 completed weeks (median 31 weeks) study weight $1190 \mathrm{~g}$ to $2460 \mathrm{~g}$ (median $1822 \mathrm{~g}$ ), and postnatal age of 7 to 19 days (median 11 days). All infants were clinically stable and in air at the time of studies and at least one hour had elapsed after their last feed.

Nine ventilated infants, gestation 27 to 36 weeks (median 28 weeks), with weights between $880 \mathrm{~g}$ to $2500 \mathrm{~g}$ (median $1300 \mathrm{~g}$ ) were studied in the closed loop ventilator mode. All infants were being ventilated with Draegar Babylog ventilators, size $3.0 \mathrm{~mm}$ endotracheal tubes, and receiving intravenous glucose or parenteral nutrition with the exception of one infant receiving all nutrition by the oral route. Ages ranged from 3 to 28 days old (median 4 days). The concentration of inspired oxygen in these infants was between $21 \%$ and $60 \%$. An assessment of the leak from the endotracheal tube was made by measurement of carbon dioxide concentrations in a plastic mask covering the face. This included a slit which allowed the endotracheal tube and nasogastric tube to pass through the mask. A partial seal was created and air was drawn from the mask at a rate of $100 \mathrm{ml} / \mathrm{min}$ as measured by an 1100 series Rotameter flowmeter. Carbon dioxide concentrations were measured by infrared analysis (Beckman LB-2 Analyser, Beckman Instruments).

All infant temperatures were within the thermoneutral range for that infant at the time of the studies. Urine was collected during the period of the study for estimation of urinary nitrogen excretion (Un) for calculation of energy expenditure values. Energy expenditure (EE) for the infants was calculated from the classical Weir equation ${ }^{23}$; see equation (8):

(8) $\mathrm{EE}(\mathrm{kcal} / \mathrm{day})=5 \cdot 67 \dot{\mathrm{V}} \mathrm{O}_{2}(\mathrm{ml} / \mathrm{min})+1.59 \dot{\mathrm{V}} \mathrm{CO}_{2}$ ( $\mathrm{ml} / \mathrm{min})-2 \cdot 17 \mathrm{Un}$ (g/day)

All studies were approved by the district ethical committee and informed consent was obtained from the parents prior to the study.

\section{Results}

VALIDATION

The constant flow of gas through the analyser was calculated to be $10.3 \mathrm{~V} / \mathrm{min}$ after three repeated burnings of ethanol showed less than $1 \%$ difference for the calculated value between each burning cycle. Mean error was calculated as [(measured value-true value)/ true value $\times 100$ where the true value is the test gas infusion. In addition the test gas infusion method, as the gold standard for reproducing $\dot{\mathrm{VCO}}_{2}$ and $\dot{\mathrm{VO}}_{2}$, was compared with values obtained from the metabolic monitor using the statistical method as proposed by Bland and Altman for limits of agreement. ${ }^{24}$ This is able to give a $95 \%$ confidence level for individual measurements when compared with an absolute or standard and accurate method (that is test gas infusion).

Mean errors in validation of the canopy mode were $1.4 \%$ and $0.2 \%$ for $\mathrm{Vo}_{2}$ and $\mathrm{VCO}_{2}$ with limits of agreement of $0.9 \mathrm{ml} / \mathrm{min}$ 
(+2SD) and $-2.3 \mathrm{mls} / \mathrm{min}(-2 \mathrm{SD})$, and 0.6 $\mathrm{ml} / \mathrm{min}(+2 S D)$ and $-1.3 \mathrm{mls} / \mathrm{min}(-2 S D)$ respectively. In validation of the ventilator mode mean errors were $-1.8 \%$ and $-5.05 \%$ for $\dot{\mathrm{V}} \mathrm{o}_{2}$ and $\dot{\mathrm{V}} \mathrm{Co}_{2}$ with limits of agreement of $1.02 \mathrm{ml} / \mathrm{min}(+2 S D)$ and $-0.74 \mathrm{ml} / \mathrm{min}$ $(-2 S D)$, and $0.93 \mathrm{ml} / \mathrm{min}(+2 S D)$ and -1.45 $\mathrm{ml} / \mathrm{min}(-2 \mathrm{SD})$ respectively.

Mean values for infants measured in the canopy mode for $\dot{\mathrm{VO}}_{2}$ and $\dot{\mathrm{V}} \mathrm{CO}_{2}$ were $6 \cdot 2$ $\mathrm{ml} / \mathrm{kg} / \mathrm{min}(0.51 \mathrm{SD})$ and $6.7 \mathrm{ml} / \mathrm{kg} / \mathrm{min}(0.6$ 1SD), RQ was 1.07 and mean energy expenditure was $45.5 \mathrm{kcal}(191 \mathrm{~kJ}) / \mathrm{kg} /$ day.

Mean values for infants measured in the ventilator mode for $\dot{\mathrm{VO}}_{2}$ and $\dot{\mathrm{V}} \mathrm{CO}_{2}$ were 4.98 $\mathrm{ml} / \mathrm{kg} / \mathrm{min}(1.091 \mathrm{SD})$ and $4.74 \mathrm{ml} / \mathrm{kg} / \mathrm{min}$ (1.08 1SD), RQ was 0.95 and mean energy expenditure was $35.5 \mathrm{kcal}(149 \mathrm{~kJ}) / \mathrm{kg} /$ day. We were not able to detect a leak of greater than $0.1 \mathrm{ml} / \mathrm{min}$ carbon dioxide from around the endotracheal tube in the three infants in whom measurements of leakage were made.

\section{Discussion}

There is a need for further understanding of energy requirements and substrate utilisation of different fuels in the preterm infant and newborn. Indirect calorimetry provides a means for studying this area. A system that is compact and mobile, providing the facility to measure both $\dot{\mathrm{VO}}_{2}$ and $\dot{\mathrm{V}} \mathrm{CO}_{2}$ simultaneously is of great potential value in making indirect calorimetry measurements. However, rigorous validation of systems for the measurement of $\dot{\mathrm{V}} \mathrm{O}_{2}$ and $\dot{\mathrm{V}} \mathrm{CO}_{2}$ are needed as errors may be significant.

The system we have used is acceptable to the infants and their parents, is non-obtrusive in the canopy mode, and may be used in the laboratory or clinical setting. Used in the ventilator mode it may be integrated into the clinical environment without any disruption to normal ventilator function.

Validation of a system by gas injection allows measurements of $\dot{\mathrm{V}} \mathrm{O}_{2}$ and $\dot{\mathrm{VCO}}_{2}$ at levels that are found in the preterm and newborn infant in conditions identical to those of normal clinical use. We did not have facility for measurement of the gas infusion separately by mass spectometric methods.

Mean errors were small for both the canopy mode and ventilation mode. These errors would result in a maximum error of $R Q$ measurement in the canopy mode of $1 \%$ and ventilator mode of $3.3 \%$. These errors are well within the previous published limits and make only a small difference to RQ estimation.

The limits of agreement for the canopy mode and the ventilator mode are of a similar order. The apparent errors when using the mean error for validation are small. By using the method of Bland and Altman ${ }^{24}$ it is possible to judge better the performance of the measuring apparatus over the whole range of values likely to be obtained in studies on newborn infants. This is preferable to using mean errors or correlation coefficients which may hide large errors in individual measurements. Our validation results show that in the small infant, particularly if less than $1000 \mathrm{~g}$, there exists the possibility of significant errors in measurement, For such infants in the ventilator mode the $95 \%$ confidence limits for $\mathrm{VO}_{2}$ and $\dot{\mathrm{VCO}}_{2}$ may be as high as $20 \%$ and $29 \%$ respectively if $\dot{\mathrm{VO}}_{2}$ and $\dot{\mathrm{VCO}}_{2}$ levels are each 5 $\mathrm{ml} / \mathrm{min}$ (maximum error $1.02 \mathrm{ml} / \mathrm{min}$ and $1.45 \mathrm{ml} / \mathrm{min}$ respectively). The largest calculated error in $R Q$ measurement for true values of 1 and 0.7 would be -0.4 and -0.3 , which are unacceptably large for most purposes. At higher rates of $\mathrm{Vo}_{2}$ and $\dot{\mathrm{V}} \mathrm{CO}_{2}$ these variations become less significant. We would suggest that limits of agreement be published when validating any new system. As this approach to presenting results has not previously been extensively used then there exists no previous data for comparison with other systems.

Measurements are difficult to make in situations of raised oxygen concentration in the ventilator mode where fluctuations may occur in inspired oxygen levels. This problem is reduced by sampling the inspired oxygen concentration after the humidifier which acts as a mixing chamber and reduces fluctuations. In addition it is important to note that the system as described for our methods used the Draeger Babylog ventilator and capture of expiratory gas from the expiratory outlet of the ventilator. In the other ventilator commonly used on our unit and other neonatal units (Sechrist infant ventilator IV-100B, EME) there is mixing, at the expiratory outlet, of gas from the infant with gas from a purging system that is a different concentration to that received by the infant. This results in considerable errors due to dilation of the expired gas. We have tried to eliminate this problem by use of an oxygen-air mixer between the external oxygen and air supplies and the ventilator blender, so that the purging gas and inspired gas are at the same concentration. However large systematic variations in $\dot{V O}_{2}$ and $\dot{\mathrm{V}} \mathrm{CO}_{2}$ and undermeasurement of these values still occur in infants measured this way. Higher flow rates at the expiratory port with this ventilator exceeding $10.3 \mathrm{~V} / \mathrm{min}$ and loss of expired gas from the collecting system would explain this error. Before using this system with any other ventilators other than the Draegar Babylog it will be necessary for investigators to validate their measurements.

Values for $\dot{\mathrm{VO}}_{2}$ and $\dot{\mathrm{V}} \mathrm{CO}_{2}$ in the infants in our study are similar to those previously published for infants measured in open hood ${ }^{4}$ systems and for those on ventilators. ${ }^{17} 18$ Energy expenditure values are also comparable with other published figures. ${ }^{25} 26$ The mean $R Q$ for those infants in the canopy mode was $1 \cdot 07$. Other studies have reported $R Q$ values $>1$ in the neonate and this suggests that lipogenesis from glucose is occurring. ${ }^{27}$ Our values were obtained over a period of 60 minutes and postprandial by at least one hour. Had we continued studies longer then net lipid synthesis from glucose may not be apparent. This equipment would be appropriate for such studies. Because the canopy mode operates in conditions of ambient air it is not recommended for use in infants receiv- 
ing supplemental oxygen via a headbox in the present configuration. This does preclude using this mode to study infants with mild to moderate bronchopulmonary dysplasia who are not on ventilators but require supplemental oxygen.

Limitations with the ventilator mode include the possible loss of expired gas from around the endotracheal tube. All our infants were ventilated with $3.0 \mathrm{~mm}$ endotracheal tubes and leaks when measured were small. Lucas et al have reported similar negligible leaks. ${ }^{17}$ If the size of leak is to be assessed with each measurement then further equipment would be required to do this with the system evaluated here. Another potential source of error is the uptake of oxygen and loss of carbon dioxide through the skin. Cartlidge and Rutter have suggested that this may account for $7 \%$ of oxygen consumption and $12 \%$ of carbon dioxide excretion for infants less than 30 weeks' gestation nursed in air during the first few days of life. ${ }^{28}$ For measurements with the canopy mode the problem of skin losses does not occur as the infant is fully encapsulated in the hood accounting for all oxygen uptake and carbon dioxide production.

In summary we have validated a portable metabolic system for use with the preterm infant and included in our validation a range of values which also encompass the newborn term infant. The system has proved easy to use in the clinical setting but because of the wide limits of agreement care must be taken in interpretation of values of $\dot{\mathrm{V}} \mathrm{O}_{2}$ and $\dot{\mathrm{V}} \mathrm{CO}_{2}$, and hence $\mathrm{RQ}$ for infants less than $1000 \mathrm{~g}$. Errors in these smallest infants are sufficiently large to preclude the use of this method alone for accurate assessment of substrate utilisation.

1 Ferrannini E. The theoretical basis of indirect calorimetry. A review. Metabolism 1988;37: 287-301.

2 Halliday D, Rennie MJ. The use of stable isotopes for diagnosis and clinical research. Clin Sci 1982;63:485-96.

3 Karlberg P. Determinations of standard energy metabolism in normal infants. Acta Paediatr Scand 1952;41(suppl 89): $1-151$.

4 Lister G, Hoffman JIE, Rudolph AM. Oxygen uptake in infants and children. A simple method for measurement. Pediatrics 1974;53:656-61.
5 Jequier E, Acheson K, Schulz Y. Assessment of energy expenditure in man. Annu Rev Nutr 1987;7:187-208.

6 Swift RW, French CF. Energy metabolism and nutrition. Washington: The Scarecrow Press, 1954.

7 Kinney JM, Felig P. The metabolic response to injury and Kinney JM, Felig P. The metabolic response to ingu
infection. New York: Grune and Stratton, 1979.

8 Stothers JK; Warner RM. Effect of feeding on neoStothers JK, Warner RM. Effect of feeding on neo-
natal oxygen consumption. Arch Dis Child 1979;54: 415-20.

9 Rebecz I, Mestyan J. Postprandial thermogenesis in human milk fed very low birthweight infants. Biol Neonate 1986;49:301-6

10 Yeh TF. Lillien LD, Leu ST, Pildes RS. Increased oxygen consumption and energy loss in premature infants following medical care procedures. Biol Neonate 1984;46: 157-62.

11 Dane HJ, Sauer PJ, Visser HKA. Oxygen consumption ind carbon dioxide production of low birth-weight

12 Scopes IW W sleep states. Biol Neonate tion in sick and premature newborn infants. Arch Dis tion in sick and premat $1966 ; 41: 407-16$.

13 Marks KH, Nardis EE, Derr JA. Day to day energy expenditure variability in low birthweight infants. Pediatr Res diture variability

14 Roberts SB, Murgatroyd PR, Crisp JA, Norhia V, Schlingenseipen $\mathbf{K H}$, Lucas A. Long-term variation in oxygen consumption rate in preterm infants. Biol Neonate 1987;52:1-8.

15 Denne SC, Kalhan SC. Glucose carbon recycling and oxidation in human newborns. Am $\mathcal{f}$ Physiol 1986;251: E71-7.

16 Marks KH, Coen P, Kerrigan JR, Francalancia NA, Nardis EE, Snider MT. The accuracy and precision of a opencircuit system to measure oxygen consumption and carbon dioxide production in neonates. Pediatr Res 1987; 21:58-65.

17 Lucas A, Norhia V, Roberts SB. Measurement of carbon dioxide rate in sick ventilated premature infants. Biol Neonate 1987;51:138-43.

18 Richardson P, Bose CL, Bucciarelli RL, Carlstrom JR. Oxygen consumption of infants with respiratory distress Oxygen consumption of infants with

19 Chwals WJ, Lally KP, Wolley MM, Mahour MD. Measured energy expenditure in critically ill infants and young children. $f$ Surg Res 1988;44:467-72.

20 Mayfield SR, Uauy $R$. Validation of a computerized indirect calorimeter for use in research studies of ventilated neonates. Pediatr Res 1986;20:414A.

21 Kalhan SC, Denne SC. Energy consumption in infants with bronchopulmonary dysplasia. $\mathcal{F}$ Pediatr 1990;116: 662-4.

22 Datex. Deltatrac operator's manual. Helsinki: Datex, Nov 1987.

23 Weir JB de V. New methods for calculating metabolic rate with special reference to protein metabolism. I Physiol (Lond) 1949;109:1-9.

24 Bland JM, Altman DG. Statistical methods for assessing agreement between two methods of clinical measure-

25 Butte NF, O'Brian Smith E, Garza C. Energy utilization of breast fed and formula fed infants. Am $\mathfrak{f}$ Clin Nutr breast fed and

26 Piedboeuf B, Chessex P, Hazan J, Pineault M, Lavoies JC. Total parenteral nutrition in the newborn infant; energy substrates and respiratory gas exchange. $\mathcal{F}$ Pediatr 1991; 118:97-102.

27 Simonson DC, Defronzo RA. Indirect calorimetry; methodological and interpretive problems. Am $\mathcal{F}$ Physiol 1990;258:E399-411.

28 Cartlidge PHT, Rutter N. Percutaneous respiration in the newborn infant. Biol Neonate 1987;52:301-6. 